\title{
Pyrolysis: an alternative technology for sustainable energy from sewage sludge
}

\author{
G. E. G. Vieira ${ }^{1}$, A. P. de Castilho ${ }^{2}$, J. Dweck ${ }^{3}$ \& L. F. Teixeira ${ }^{1}$ \\ ${ }^{1}$ Laboratory of Testing and Development on Biomass and Biofuels, \\ Federal University of Tocantins, Brazil \\ ${ }^{2}$ Center for Research and Development, PETROBRAS, Brazil \\ ${ }^{3}$ Chemical Engineering, Federal University of Rio de Janeiro, Brazil
}

\begin{abstract}
Sewage sludge production tends to grow due to the increased amount of treated sewage. Additionally, the limitations of the disposal lead to the need for alternative processes for technological use of this residue and pyrolysis is a promising way to obtain products with potential energy, such as bio-oil. In this work, the characterization of wastewater and the application of catalytic pyrolysis sludge had the addition of $\mathrm{Fe}_{2} \mathrm{O}_{3}$ as a catalyst, in order to optimize the bio-oil production. The sewage sludge characterization presented five values: moisture content $6.85 \%$ $(\mathrm{m} / \mathrm{m})$, ash $33.33 \%(\mathrm{~m} / \mathrm{m})$, volatile solids $54.99 \%(\mathrm{~m} / \mathrm{m})$, fixed carbon $4.83 \%$ $(\mathrm{m} / \mathrm{m})$ and calorific value $21.80 \mathrm{MJ}_{\mathrm{kg}}{ }^{-1}$. The thermal behavior of the sewage sludge was analyzed by thermogravimetric analysis (TGA), to check the catalytic activity of iron oxide with increasing volatilization and cracking of the organic substances present in sewage sludge, and thus reducing the formation of solid fraction. In the pyrolysis process an experimental planning of $2^{3}$ with a central point has been used, and the effect of variables was analyzed at different process temperatures $\left(450^{\circ} \mathrm{C}, 500^{\circ} \mathrm{C}\right.$ and $\left.550^{\circ} \mathrm{C}\right)$, time $(120 \mathrm{~min}, 150 \mathrm{~min}$ and $180 \mathrm{~min})$, heating rates $\left(10^{\circ} \mathrm{C} \cdot \mathrm{min}^{-1}, 20^{\circ} \mathrm{C} \cdot \mathrm{min}^{-1}\right.$, and $\left.30^{\circ} \mathrm{C} \cdot \mathrm{min}^{-1}\right)$ in the yield of obtained products. Statistical analysis showed that the temperature influenced the yields of bio-oil in a positive and significant way, the maximum yield was in the order of $15.60 \%(\mathrm{~m} / \mathrm{m})$ under the following conditions: temperature $550^{\circ} \mathrm{C}$, time 180 min and $10^{\circ} \mathrm{C} \cdot \mathrm{min}^{-1}$ heating rate. Moreover, the bio-oil obtained from sewage sludge by pyrolysis can be used in the chemical industry and in power generation. Keywords: sewage, sludge, pyrolysis, analysis, thermogravimetric, biomass.
\end{abstract}




\section{Introduction}

Biomass is one of the main and most important renewable energy sources, including through their conversion a wide range of materials, technologies and end-use applications products such as power generation, heat, biofuels for transport and supplies for chemical industries. Its generation and the efficient use appear as one of the biggest challenges of contemporary society (Bridgwater [1]).

Among the biomasses, the residual sewage sludge generated by the sewage treatment plants, is a major environmental problem for sanitation companies. Its management is a complex activity and it has a high cost when poorly executed. As a result, it can compromise the health benefits expected from such systems (Vieira et al. [2]).

Sewage sludge is composed of a heterogeneous mixture of undigested organic compounds and inorganic materials. In its constitution, it has a variety of functional groups, such as acids, alcohols, amines, amides, nitriles, ketones and hydrocarbons (Pedroza et al. [3]).

Different destinations are used for sewage sludge generated in treatment plants, among these processes are included the disposal in landfills, agricultural use, incineration and composting. Pyrolysis is an alternative that has been considered one of the promising ways. Additionally, its application to sewage sludge to obtain products with potential energy shows up as a way to leverage and add value to this waste turning it into raw material; consequently, reducing the environmental impacts caused by sewage sludge, as well as improper disposal. Moreover, the fact the sewage sludge to be abundant worldwide, makes the application of the pyrolysis process to that waste well successful and of great scientific and technological interest (Fonts et al. [4]; Gao et al. [5]).

In this context, this study aimed at the implementation of the pyrolytic process to sewage sludge with the addition of $\mathrm{Fe}_{2} \mathrm{O}_{3}$ in a proportion of $5 \%(\mathrm{~m} / \mathrm{m})$ to evaluate the performance of the fractions obtained and thus to determine the best process conditions in the pyrolysis, aiming a higher yield of bio-oil. Sewage sludge was characterized in order to discuss its influence in the pyrolysis and performed thermogravimetric analysis (TGA) to observe its thermal behavior and check the catalytic activity of the iron oxide.

\section{Materials and methods}

\subsection{Collection and drying of sewage sludge}

The sewage sludge used in this project was produced in a UASB (Upflow Anaerobic Sludge Blanket), during the dry season, in a sewage treatment plant, located in Palmas, Tocantins, Brazil.

The drying of the sewage sludge was performed in handmade solar oven until the constant weight. After that, it was milled using a mill and homogenized in a Tyler sieve with apertures of $0.355 \mathrm{~mm}$. 


\subsection{Characterization of sewage sludge}

The moisture of the sewage sludge was determined according to ASTM 3173 standard [6]. In addition, the content of volatile solids and ash were obtained according to ASTM 2415 [7] and the fixed carbon was determined by the difference. The gross calorific value was determined using the Parr bomb calorimeter 1341, Model 1241, performed in excess of $\mathrm{O}_{2}$ and pressure of 20 to $30 \mathrm{~atm}$.

\subsection{Thermogravimetric analysis (TGA) and differential thermal analysis (DTA)}

The evaluation of the thermal behavior of the sewage sludge was performed by thermogravimetric analysis (TGA), using a simultaneous equipment TGA/DTA of the TA Instruments, model 2960. The analyses were performed in an environment with air flow and nitrogen, both with a flow of $100 \mathrm{ml} . \mathrm{min}^{-1}$, a heating rate of $10^{\circ} \mathrm{C} \cdot \mathrm{min}^{-1}$ from the temperature $30^{\circ} \mathrm{C}$ to $1000^{\circ} \mathrm{C}$ in alumina crucibles. The air flow allowed us to analyze what happens during the combustion of sewage sludge and the nitrogen flow to what occurs during the pyrolysis of sewage sludge. The TGA curves (thermogravimetric), DTG (derivative thermogravimetric) and DTA (differential thermal analysis) were obtained using the software TA Instruments (Universal Analysis Software).

\subsection{Pyrolysis process}

In the pyrolysis process, an amount of 40 grams of sewage sludge was used with the addition of $5 \%(\mathrm{~m} / \mathrm{m}) \mathrm{Fe}_{2} \mathrm{O}_{3}$. The fixed-bed reactor operates in an inert environment promoted by nitrogen flow, which occurs from the right to the left in the quartz tube, promoting the exit of gases to a condensing system, which leads to a system of collection and removal of condensational products as shown by the schematic drawing of Figure 1.

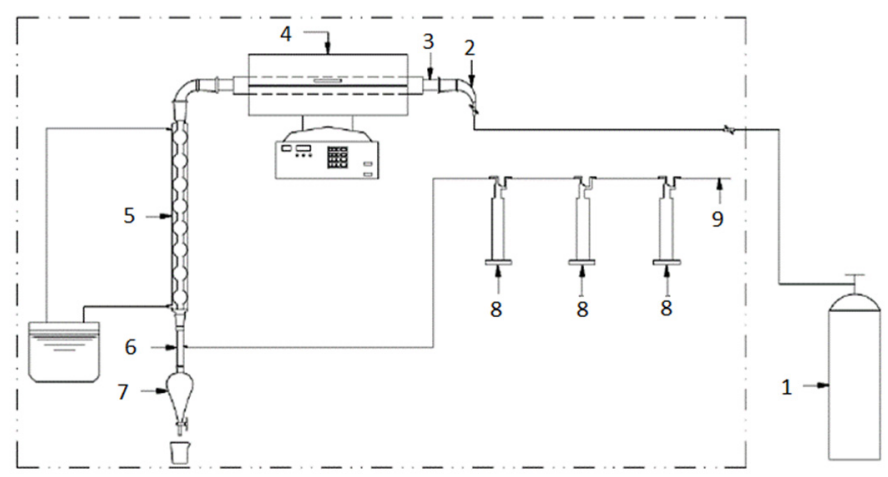

Figure 1: Scheme of the pyrolysis system. Legend: (1) nitrogen cylinder; (2) inert gas inlet; (3) quartz reactor tube; (4) oven; (5) condenser; (6) gas outlet; (7) separating funnel; (8) gas scrubbers; and (9) gases outlet. 


\subsection{Statistical design of the pyrolysis process}

To carry out the pyrolysis experiments, $2^{3}$ factorial design with a central point was adopted to assess the yields of products for process parameters, aiming the production of bio-oil. The factors used in the process were: temperature $\left({ }^{\circ} \mathrm{C}\right)$, time (min) and heating rate $\left({ }^{\circ} \mathrm{C} \cdot \mathrm{min}^{-1}\right)$ (as shown in table 1). Furthermore, 9 experiments were performed, one being in the central point in triplicate random.

Table 1: Levels of factors used in the experimental design with $2^{3}$ central point in the thermocatalytic pyrolysis process of sewage sludge.

\begin{tabular}{|c|c|c|c|}
\hline Factors & $\begin{array}{c}\text { Inferior level } \\
(-)\end{array}$ & $\begin{array}{c}\text { Central point } \\
(\mathbf{0})\end{array}$ & $\begin{array}{c}\text { Superior level } \\
(+)\end{array}$ \\
\hline Temperature $\left({ }^{\circ} \mathrm{C}\right)$ & 450 & 500 & 550 \\
\hline Time $(\mathrm{min})$ & 120 & 150 & 180 \\
\hline Rate $\left({ }^{\circ} \mathrm{C} / \mathrm{min}\right)$ & 10 & 20 & 30 \\
\hline
\end{tabular}

\section{Results and discussion}

\subsection{Characterization of sewage sludge}

Immediate analysis is fundamental to the study of the technological route of reuse of biomass waste and its application in the pyrolysis processes. Table 2 presents the average results of the humidity, volatile solids, ash, fixed carbon and a gross calorific value.

Table 2: Characteristics of sewage sludge.

\begin{tabular}{|c|c|c|c|}
\hline \multicolumn{4}{|c|}{ Immediate analysis } \\
\hline $\begin{array}{c}\text { Humidity } \\
(\% \mathrm{~m} / \mathrm{m})\end{array}$ & $\begin{array}{c}\text { Volatile solids } \\
(\% \mathrm{~m} / \mathrm{m})\end{array}$ & $\begin{array}{c}\text { Ash } \\
(\% \mathrm{~m} / \mathrm{m})\end{array}$ & $\begin{array}{c}\text { Fixed carbon } \\
(\% \mathrm{~m} / \mathrm{m})\end{array}$ \\
\hline 6.85 & 54.99 & 33.33 & 4.83 \\
\hline \multicolumn{3}{|c|}{ Gross calorific value $\left({\left.\mathrm{MJ} . \mathrm{kg}^{-1}\right)}^{21.80}\right.$} \\
\hline
\end{tabular}

Sewage sludge had a moisture content similar to what (Sanchez et al. [8]) obtained, $6.8 \%(\mathrm{~m} / \mathrm{m})$, to analyze anaerobic sludge. The presence of moisture in the sludge is directly associated with factors such as weather conditions, seasonality, origin and treatment which the sewage was submitted. Its determination is relevant because of its influence on the energy consumption of the pyrolysis, where (when) the loss of moisture in the form of water vapor has a strong endothermic reaction.

The volatile solids content was $54.99 \%(\mathrm{~m} / \mathrm{m})$. Among the organic compounds that make up the fraction of the volatile solids are lignocellulosic materials, such 
as cellulose, hemicellulose and lignin, which have the characteristic of volatilization between 200 and $400^{\circ} \mathrm{C}$, humic acids and carboxylic acids (Pedroza et al. [3]). Its importance is due to the fact that the organic material undergoes desorption followed by volatilization in the first stages of the pyrolysis, and subsequently, it passes through the cracking and the chemical rearrangement, forming new compounds which will constitute bio-oil when it is condensed.

The percentage of sewage sludge ash was close to what Sanchez et al. [8] and Gascó et al. [9] found, respectively $32.4 \%(\mathrm{~m} / \mathrm{m})$ and $32.5 \%(\mathrm{~m} / \mathrm{m})$. The high ash content in the sewage sludge promotes the contact between the metals and the organic matter, making that the volatile detachment reactions occur at lower temperatures (Mohan et al. [10]). Along with the fixed carbon and organic matter not degraded thermally, the ash, composes the resultant solid fraction of the pyrolysis process.

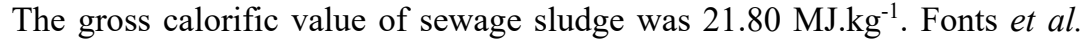
[11] used in his study three types of sludge and presented the following calorific

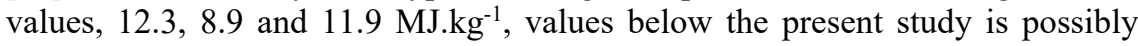
related to higher volatile content compared to that observed by Fonts et al. [11] $47 \%, 38.3 \%$ and $46.6 \%$. The gross calorific value can be influenced by the type of biomass, chemical composition as well as the humidity and the ash content if the organic matter was digested or not (Vieira et al. [2]).

\subsection{Thermogravimetric analysis and differential thermal analysis}

The thermal behavior of the sewage sludge in this study was made by thermogravimetric analysis (TGA), derivative thermogravimetric (DTG), and differential thermal analysis (DTA). The figure 2 presents the TGA's, DTG's, and DTA's curves of the sewage sludge in an oxidizing atmosphere.

In the TGA/DTG curve of the sewage sludge in air, three events are observed. First, between $35.39^{\circ} \mathrm{C}$ and $100.1^{\circ} \mathrm{C}$, showed $4.62 \%$ of mass loss percentage at the temperature of $100.6^{\circ} \mathrm{C}$, corresponding the free water loss. The second event, observed between $100.6^{\circ} \mathrm{C}$ and $141.2^{\circ} \mathrm{C}$, is related to the dehydration regarding to the water adsorption on sewage sludge pores, corresponding to a mass loss of $6.44 \%$, amount close to the one obtained in determining the moisture content by classical thermal gravimetric analysis $(6.85 \% \mathrm{~m} / \mathrm{m})$. Dweck et al. [12], after the analysis of sewage sludge, observed that the free water is released until $150^{\circ} \mathrm{C}$, before the combustion stage. In the DTA curve, it can be seen the two endotherms peaks, that are related to these two events.

The third event presents two overlapping pikes between $141.26^{\circ} \mathrm{C}$, and $566.50^{\circ} \mathrm{C}$, regarding the release of volatile material. The loss in this interval was equal to $62.97 \%$, therefore, generating $37.03 \%$ of ashes. In this phase, the biggest mass loss occurs, having heat release during combustion, as can be observed through the exothermic event in DTA's curve, in figure 2.

From the TGA/DTG's curves, placed in figure 3, the nitrogen atmosphere analysis in the pyrolysis of sewage sludge, three events happen. Two events can be identified, the first one between $31.39^{\circ} \mathrm{C}$ and $105.50^{\circ} \mathrm{C}$, and the second one between $105.50^{\circ} \mathrm{C}$ and $138.59^{\circ} \mathrm{C}$, corresponding to the loss of moisture and light volatiles materials, with a mass loss percentage of $4.61 \%$ and $5.89 \%$, respectively 


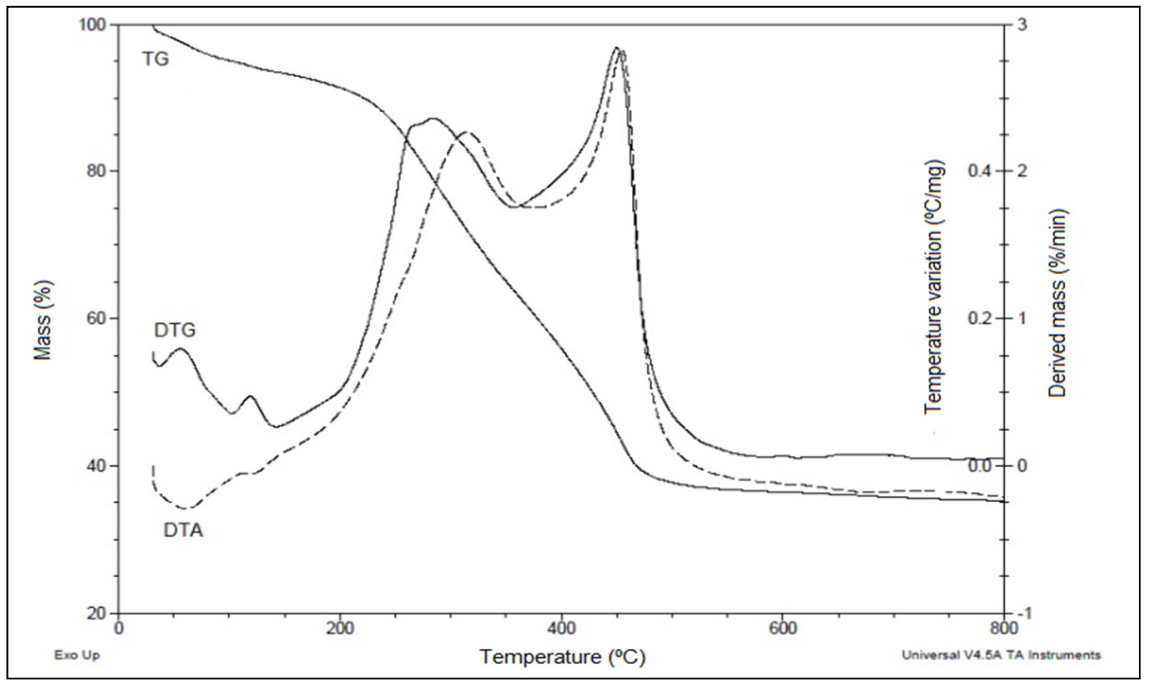

Figure 2: TGA's, DTG's, and DTA's curves of the sewage sludge in air.

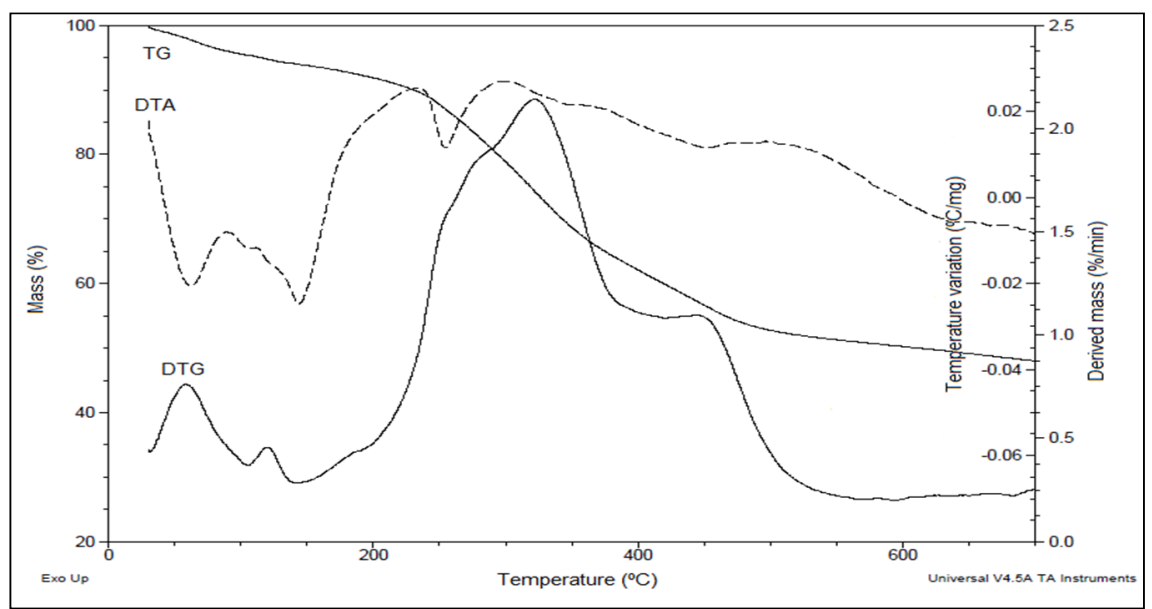

Figure 3: TGA's, DTG's, and DTA's curves of the sewage sludge in nitrogen.

in the first and the second events, both corresponding DTA peaks are endothermic, likewise happened in the in air analysis at this temperature interval.

In the third event, between $138.59^{\circ} \mathrm{C}$ and $566.50^{\circ} \mathrm{C}$, the overlapped peaks indicate the liberation by cracking of organic materials contained in the sewage. This stage corresponds to the $49.07 \%$ of mass loss from the sewage sludge. The sewage sludge's range of decomposition of organic matter is very close to the 
result obtained by Karayildirim et al. [13], that corresponded to a thermal decomposition range from 200 to $500^{\circ} \mathrm{C}$, indicating the volatile material release.

Figure 4 represents a subtraction of the TGA's curve in inert atmosphere with the TGA's curve in oxidizing atmosphere of the sewage sludge with either added catalyzer $\left(\mathrm{Fe}_{2} \mathrm{O}_{3}\right)$, resulting in the carbonaceous residue's curve. In this procedure, is observed that the water losses do not affect the outcome for both events are not influenced by the analysis atmosphere, being, therefore, detected in the same form and same temperature ranges in pyrolysis, or combustion of sewage sludge.

When the $239^{\circ} \mathrm{C}$ temperature is reached, it can be observed that the mass loss of the sewage with iron oxide becomes greater than the mass loss in the corresponding curve to the sewage sample without a catalyzer. The maximum mass loss point occurs at $479^{\circ} \mathrm{C}$, where the sewage without a catalyzer presents $20.48 \%$ of organic material, whereas the sample with iron oxide presents $14.59 \%$, indicating a greater conversion. Alexandre [14], when evaluating the pyrolysis sewage's behavior with the addition of calcium oxide observed that the maximum mass loss point happened at $478.5^{\circ} \mathrm{C}$, showing $18.7 \%$ of mass percentage.

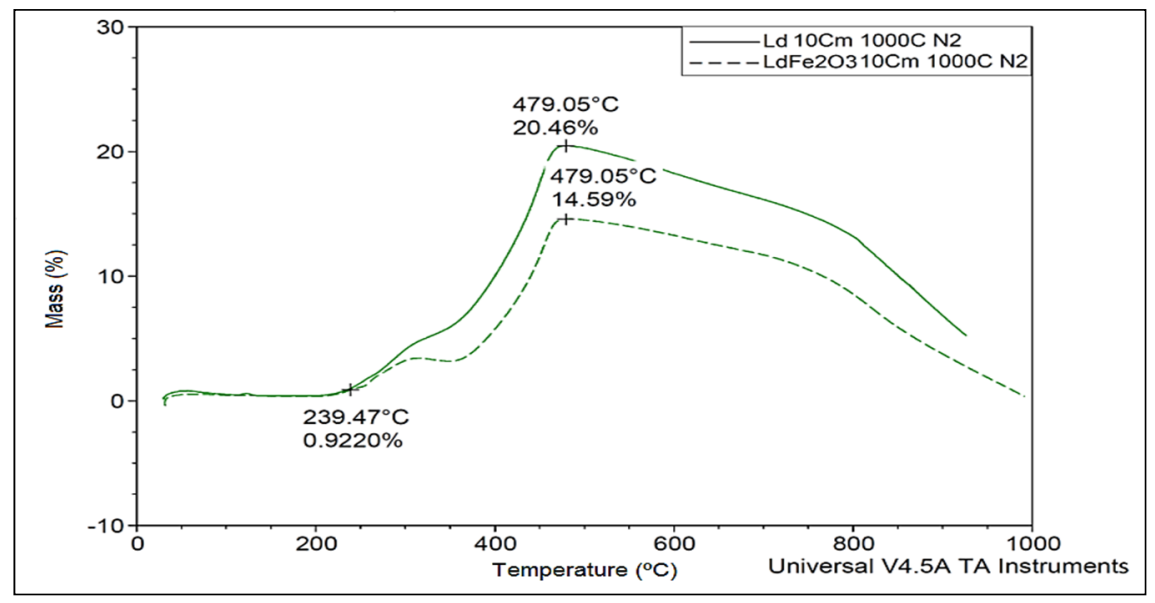

Figure 4: Beginning of the catalytic activity of the $\mathrm{Fe}_{2} \mathrm{O}_{3}$ in nitrogen.

\subsection{Performance of the products obtained from the pyrolysis of sewage sludge}

The results obtained from the statistic planning were treated to estimate the coefficients of the main effects and its interactions, investigating the parameter that influence the product's performances obtained through the pyrolysis process of sewage sludge. The performance of the bio-oil, aqueous, solid, and gas fractions are presented in table 3 .

According to the Pareto chart, generated from the factorial planning shown in figure 5, indicates that the temperature growth from $450^{\circ} \mathrm{C}$ to $550^{\circ} \mathrm{C}$ propitiated positive effect to the bio-oil production in the pyrolysis process of sewage sludge. Inguanzo et al. [15], observed that the liquid fraction's performance was greater 
when the temperature increases from $450^{\circ} \mathrm{C}$ to $650^{\circ} \mathrm{C}$. Above this temperature, it was not observed a fraction's growth. According to Fonts et al. [11], the decrease of bio-oil temperatures above $650^{\circ} \mathrm{C}$ occurs because of the secondary reactions, such as cracking, elevating the production of gas fraction. The heating variation rate from $10^{\circ} \mathrm{C} \cdot \mathrm{min}^{-1}$ until $30^{\circ} \mathrm{C} \cdot \mathrm{min}^{-1}$ and the process span from 120 minutes to 180 minutes did not present relevant effects in the performance, as well as its interactions, shown in figure 5. In this way, the obtained data indicate that the biooil making can be performed base on parameters that cause less energy expenditure, like less time and greater heating rate.

Table 3: $\quad$ Planning $2^{3}$ results obtained for the product obtained in the pyrolysis process of the sewage sludge with addition of Fe2O3. Label: OF: biooil fraction; AF: aqueous fraction; SF: solid fraction; GF: gas fraction.

\begin{tabular}{|c|c|c|c|c|c|c|c|}
\hline \multirow{2}{*}{ Experiment } & \multicolumn{3}{|c|}{ Factor } & \multicolumn{4}{c|}{ Performance (\%) } \\
\cline { 2 - 8 } & $\begin{array}{c}\text { Temp. } \\
\left({ }^{\mathbf{}} \mathbf{C}\right)\end{array}$ & $\begin{array}{c}\text { Time } \\
(\mathbf{m i n})\end{array}$ & $\begin{array}{c}\text { Rate } \\
\left({ }^{\left.{ }^{\circ} \mathbf{C} \cdot \mathbf{m i n}^{-1}\right)}\right.\end{array}$ & $\mathbf{O F}$ & $\mathbf{A F}$ & $\mathbf{S F}$ & $\mathbf{G F}^{*}$ \\
\hline 1 & 450 & 120 & 10 & 13.82 & 12.59 & 60.92 & 12.67 \\
\hline 2 & 550 & 120 & 10 & 15.53 & 14.40 & 58.90 & 11.16 \\
\hline 3 & 450 & 180 & 10 & 13.83 & 12.06 & 60.97 & 13.14 \\
\hline $\mathbf{4}$ & $\mathbf{5 5 0}$ & $\mathbf{1 8 0}$ & $\mathbf{1 0}$ & $\mathbf{1 5 . 6 0}$ & $\mathbf{1 3 . 2 8}$ & $\mathbf{5 6 . 5 2}$ & $\mathbf{1 4 . 6 0}$ \\
\hline 5 & 450 & 120 & 30 & 13.53 & 12.40 & 62.87 & 11.20 \\
\hline 6 & 550 & 120 & 30 & 15.37 & 13.84 & 57.77 & 13.02 \\
\hline 7 & 450 & 180 & 30 & 14.39 & 13.16 & 61.39 & 11.06 \\
\hline 8 & 550 & 180 & 30 & 15.53 & 13.51 & 59.81 & 11.16 \\
\hline 9 & 500 & 150 & 20 & 15.23 & 13.21 & 59.63 & 11.93 \\
\hline
\end{tabular}

*Performance calculation of the gas fraction made by difference.

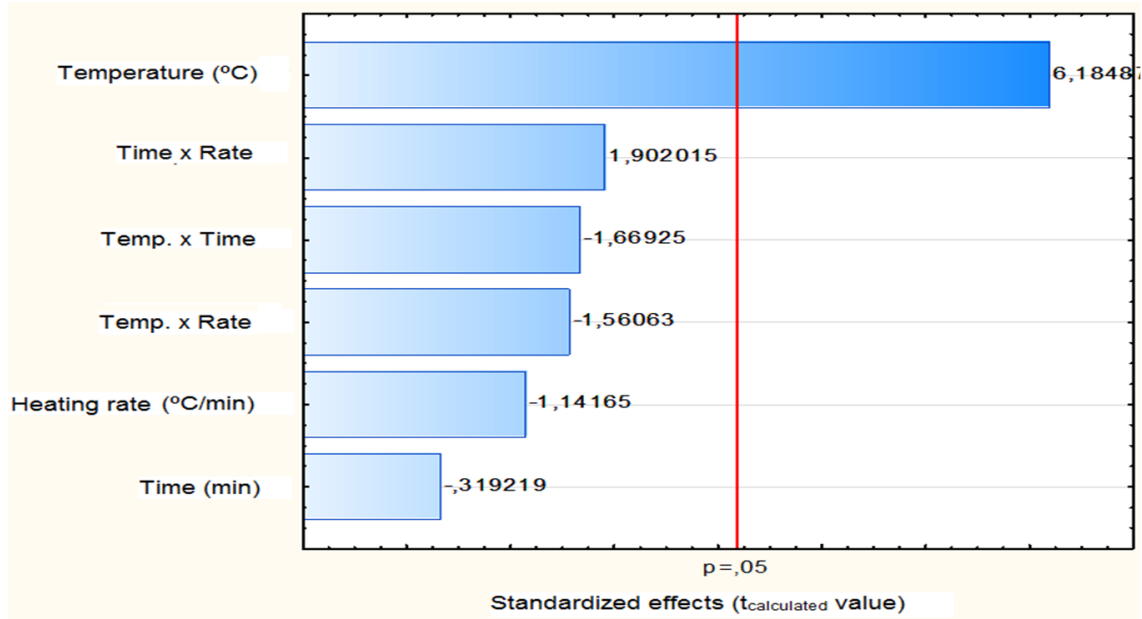

Figure 5: Pareto chart obtained from the $2^{3}$ factorial planning with central point to the bio-oil making from the pyrolysis of sewage sludge with $\mathrm{Fe}_{2} \mathrm{O}_{3}$. 
The $\mathrm{R}^{2}$ values found from the regression coefficients indicate a good mathematical model adjustment, meaning that $93.94 \%$ of the variations are explained or adjusted by presented model by eqn (1), at a $95 \%$ confidence interval.

$$
14.98+0.99 X 1-0.05 X 2-0.18 X 3-0.27 X 4-0.25 X 5-0.31 X 6
$$

The variance analysis for the bio-oil production is presented in table 4. For confirmation of the utilized parameters, the $\mathrm{F}$ test was performed, where, to be statistically significant, the $\mathrm{F}$ value obtained from the regression, described as

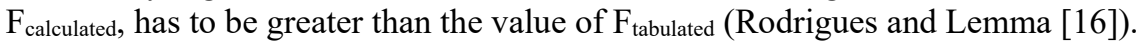
Comparing the value of $F_{\text {calculated }}$ from the fractions with the value of $F_{\text {tabulated, a }}$ relevant regression to the bio-oil is identified. Therefore, the experimental data are well represented by the model obtained for significant variables, and can be used for predictive purposes among the factors studied.

Table 4: ANOVA for bio-oil production from pyrolysis of sewage sludge. Label: S.Q.: Sum of Squares; F.D.: Freedom Degree; M.S.: Mean Square.

\begin{tabular}{|c|c|c|c|c|c|}
\hline Variation factors & S. Q. & F. D. & M. S. & F calculated & P-valor \\
\hline Regression & 5.64 & 6 & 0.94 & 10.74 & 0.0005 \\
\hline Error & 0.35 & 4 & 0.0875 & & \\
\hline SS Total & 5.76 & 10 & & & \\
\hline $\mathrm{R}^{2}=0.93941 ; \mathrm{F}_{\text {tabulated }}(6 ; 4 ; 0.05)=6.16$ & & & & \\
\hline
\end{tabular}

The bio-oil maximum performances were found in higher temperature conditions, according to the observed in the response surface graph generated from the model presented in Figure 6. The maximum bio-oil performance was $15.60 \%$, which corresponds to the experiment performed with the following parameters: temperature of $550^{\circ} \mathrm{C}$, heating rate of $10^{\circ} \mathrm{C} \cdot \mathrm{min}^{-1}$, and residence time of 180 minutes. Whereas the minimum bio-oil performance was $13.53 \%$, obtained in the experimental conditions at a temperature of $450^{\circ} \mathrm{C}$, heating rate of $30^{\circ} \mathrm{C} \cdot \mathrm{min}^{-1}$, and residence time of 120 minutes, as it is presented in Figure 6.

\section{Conclusion}

The sewage sludge's characteristics in this study showed a high percentage of volatile solids $(54.99 \% \mathrm{~m} / \mathrm{m})$ and ashes $(33.33 \% \mathrm{~m} / \mathrm{m})$, and low percentages of moisture in the sample $(6.85 \% \mathrm{~m} / \mathrm{m})$. The low moisture is desirable in the biomass to be applied in the pyrolysis process. The high percentage of ashes is a consequence of inorganic compounds from sewage production.

This study gave means to watch the catalytic activity of the iron oxide by the TGA/DTG/DTA, simultaneously with the increase volatilization and cracking of organic substances present in the sewage sludge. Therefore, the ability of this 


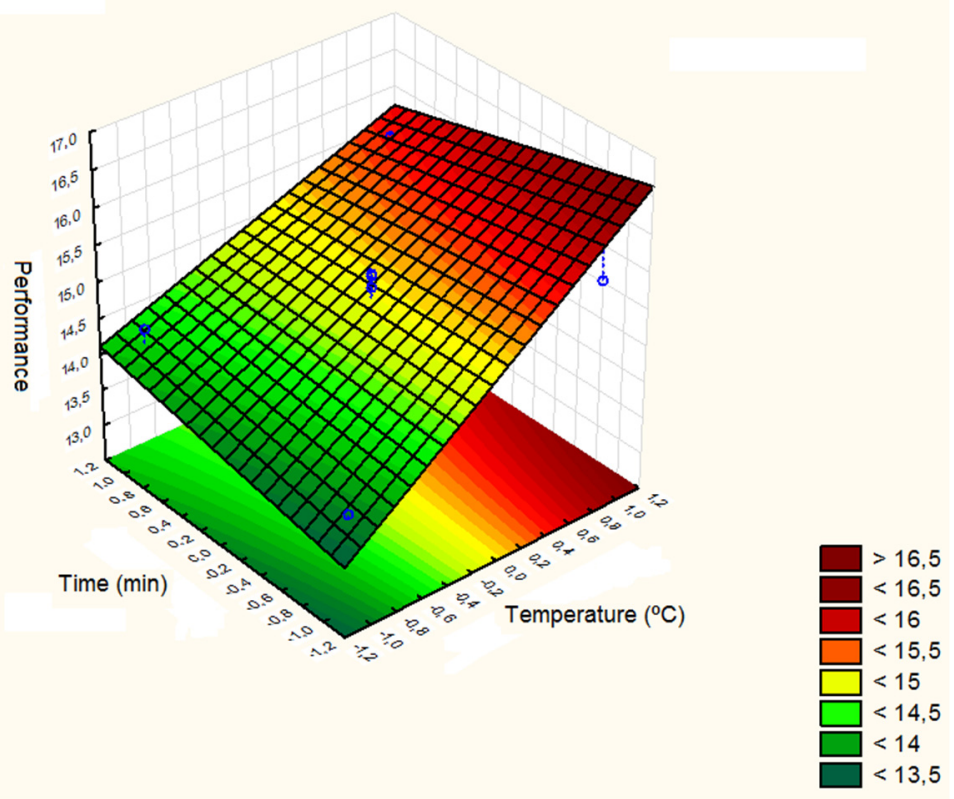

Figure 6: Response surface for the making of bio-oil from the pyrolysis of sewage sludge.

process in reducing the solid fraction was recognized when compared to the pyrolysis of sewage sludge without the addition of iron oxide.

In the pyrolysis of sewage sludge, using a proportion of $5 \%(\mathrm{~m} / \mathrm{m})$ of iron dioxide, the best conditions for obtaining bio-oil through $2^{3}$ factorial statistical design with central point, were in the experiment that used the highest temperature $\left(550^{\circ} \mathrm{C}\right)$, greatest time $(180 \mathrm{~min})$, and the smallest heating rate $\left(10^{\circ} \mathrm{C} \cdot \mathrm{min}^{-1}\right)$, with a performance of $15.6 \%(\mathrm{~m} / \mathrm{m})$, where the temperature was the unique parameter to be influenced significantly. Thus, it could be observed that the sewage sludge in this study can be used as an energetic alternative in big cities, implying, therefore, in a sustainable and economic gain.

\section{References}

[1] Bridgwater, A. V., Review of fast pyrolysis of biomass and product upgrading. Biomass and Bioenergy, v. 38, pp. 68-94, 2012.

[2] Vieira, G. E. G., Romero, G. A., Sella, S. M., Damasceno, R. N.\& Pereira, R. G., Low temperature conversion (LTC) - An alternative method to treat sludge generated in an industrial wastewater treatment station - Batch and continuous process comparison. Bioresource Technology, v.100, pp. 1544$1547,2009$. 
[3] Pedroza, M. M, Sousa, J. F., Vieira, G. E. G. \& Bezerra, M. B. D. Characterization of the products from the pyrolysis of sewage sludge in $1 \mathrm{~kg} / \mathrm{h}$ rotating cylinder reactor. Journal of Analytical and Applied Pyrolysis, v. 105, pp. 108-115, 2014.

[4] Fonts, I., Gea, G., Azuara, M., Ábrego, J. \& Arauzo, J., Sewage sludge pyrolysis for liquid production: A review. Renewable and Sustainable Energy Reviews. v. 16, pp. 2781-2805, 2012.

[5] Gao, N., Li, J., Qi, B., Li, A., Duan, Y., \& Wang, Z., Thermal analysis and products distribution of dried sewage sludge pyrolysis. Journal of Analytical and Applied Pyrolysis. v. 105, pp. 43-48, 2014.

[6] American Society for Testing and Materials, ASTM D 3173 Standard Test of Humidity, 1985.

[7] American Society for Testing and Materials, ASTM D 2415 Standard Test Method for Ash Determination, 1986.

[8] Sanchez, M. E., Menédez, J. A., Domínguez, A., Pis, J. J., Martínez, O., Calvo, L. F, \& Bernad, P. L., Effect of pyrolysis temperature on the composition of the oils obtained from sewage sludge. Biomass and Bioenergy, v. 33, pp. 933-940, 2009.

[9] Gascó, G., Cueto, M. J., \& Méndez, A., The effect of acid treatment on the pyrolysis behavior of sewage sludges. J. Anal. Appl. Pyrolysis, v. 80, pp. 496-501, 2007.

[10] Mohan, D., Pittman Jr., C., \& Steele, P. H., Pyrolysis of Wood/Biomass for Bio-oil: A Critical Review. Energy \& Fuels, v.20, pp. 848-889, 2006.

[11] Fonts, I., Azuara, M., Gea, G. \& Murillo, M. B., Physicochemical properties of product liquid from pyrolysis of sewage sludge. Energy \& Fuels, v. 23, pp. 4121-4128, 2009.

[12] Dweck, J., Morais, L. C., Meneses, J. C. \& Büchler, P. M., Thermal analysis of municipal sludge waste combustion, Materials Science Forum, v. 530531, pp. 740-746, 2006.

[13] Karayildirim, T., Yanik, J. \& Yuksel, B., Characterization of products from pyrolysis of waste sludges. Energy Fuel, v. 85, pp. 1498-1508, 2006.

[14] Alexandre, G. P., Avaliação da produção de bio-óleo por termocatálise com óxido de cálcio de lodo de esgoto doméstico, Dissertação (Mestrado em Agroenergia), Universidade Federal do Tocantins: Palmas, pp. 1-121, 2013.

[15] Inguanzo, M., Domínguez, A., Menéndez, J. A., Blanco, C. G. \& Pis, J. J., On the pyrolysis of sewage sludge: the influence of pyrolysis conditions on solid, liquid and gas fractions. Journal of Analytical and Applied Pyrolysis, v. 63, n.1, pp. 209-222, 2002.

[16] Rodrigues, M. I. \& Lemma, A. F., Planejamento de experimentos e otimização de processos. Ed. Cárita: Campinas-SP, pp. 1-358, 2009. 